\title{
man \\ Optimizing the Sharpening Process of Hybrid-Bonded Diamond Grinding Wheels by Means of a Process Model
}

\author{
Eckart Uhlmann ${ }^{1,2}$ and Arunan Muthulingam ${ }^{1, *}$ \\ 1 Institute for Machine Tools and Factory Management (IWF), Technical University Berlin, Pascalstr. 8-9, \\ 10587 Berlin, Germany; eckart.uhlmann@iwf.tu-berlin.de \\ 2 Fraunhofer Institute for Production Systems and Design Technology, Technical University Berlin, \\ Pascalstr. 8-9, 10587 Berlin, Germany \\ * Correspondence: arunan.muthulingam@iwf.tu-berlin.de; Tel.: +49-(0)30-314-22903; Fax: +49-(0)30-314-25895
}

Citation: Uhlmann, E.; Muthulingam, A. Optimizing the Sharpening Process of Hybrid-Bonded Diamond Grinding Wheels by Means of a Process Model. Machines 2022, 10, 8 . https://doi.org/10.3390/machines 10010008

Academic Editor:

Angelos P. Markopoulos

Received: 15 November 2021

Accepted: 17 December 2021

Published: 22 December 2021

Publisher's Note: MDPI stays neutral with regard to jurisdictional claims in published maps and institutional affiliations.

Copyright: (C) 2021 by the authors. Licensee MDPI, Basel, Switzerland. This article is an open access article distributed under the terms and conditions of the Creative Commons Attribution (CC BY) license (https:// creativecommons.org/licenses/by/ $4.0 /)$.

\begin{abstract}
The grinding wheel topography influences the cutting performance and thus the economic efficiency of a grinding process. In contrary to conventional grinding wheels, super abrasive grinding wheels should undergo an additional sharpening process after the initial profiling process to obtain a suitable microstructure of the grinding wheel. Due to the lack of scientific knowledge, the sharpening process is mostly performed manually in industrial practice. A CNC-controlled sharpening process can not only improve the reproducibility of grinding processes but also decrease the secondary processing time and thereby increase the economic efficiency significantly. To optimize the sharpening process, experimental investigations were carried out to identify the significant sharpening parameters influencing the grinding wheel topography. The sharpening block width $1_{\mathrm{Sb}}$, the grain size of the sharpening block $\mathrm{d}_{\mathrm{kSb}}$ and the area-related material removal in sharpening $\mathrm{V}^{\prime \prime} \mathrm{Sb}$ were identified as the most significant parameters. Additional experiments were performed to further quantify the influence of the significant sharpening parameters. Based on that, a process model was developed to predict the required sharpening parameters for certain target topographies. By using the process model, constant work results and improved process reliability can be obtained.
\end{abstract}

Keywords: tool grinding; conditioning process; process model; block sharpening process; surface quality

\section{Introduction}

The increasing demand for productive grinding processes that meet economic and quality standards leads to the constant development of grinding tools and associated dressing tools [1]. An essential part of the grinding technology is the dressing process for the regeneration of the macro- and microgeometry of the grinding wheel topography. The dressing process is divided into profiling and sharpening. Through the sharpening process a sufficient chip space is achieved, and the required cutting grains are exposed from the bond by resetting the bond material. The sharpening process therefore determines the cutting ability and additionally influences the grinding process forces and the surface quality of the ground components [2-4]. The reduction in the process forces can lead to less thermal damage to the ground workpiece due to the lower process-related heat generation [4-6]. Grinding wheels adapted to the application can lead to constant work results and process parameters, which lead to improved process reliability [1]. However, due to the lack of scientific knowledge, the sharpening process is mostly performed manually in industrial practice by holding a sharpening block against the grinding wheel and thus does not meet the requirements of highly accurate, secure and automated manufacturing.

Figure 1 illustrates the qualitative course of the grinding behavior for an insufficiently sharpened, over sharpened and with optimized sharpening parameters and tools sharpened grinding wheel [7]. An insufficiently sharpened grinding wheel results in high grinding forces and low surface roughness due to the low grain protrusion. The necessary cutting 
grains as well as the required chip space are ensured only through the time-consuming grinding-in phase (Figure 1a). On the other hand, an over-sharpened grinding wheel is characterized by a high grain protrusion and leads to high surface roughness. Due to the high grain protrusion the process initially leads to low grinding forces, which reach a constant level in the course of the process by grain breakouts and rounded grains (Figure 1b). Grinding wheels that are sharpened with optimized sharpening parameters and tools require a very short grinding-in phase in order to achieve the steady-state process condition. Thus, a well-sharpened grinding wheel is of great importance for an economical manufacturing process to achieve a steady-state process behavior and to ensure an almost constant workpiece quality (Figure 1c).

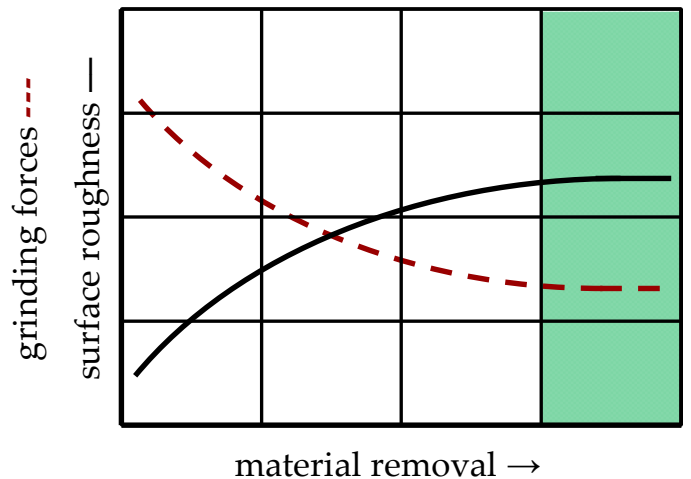

(a) Insufficiently sharpened

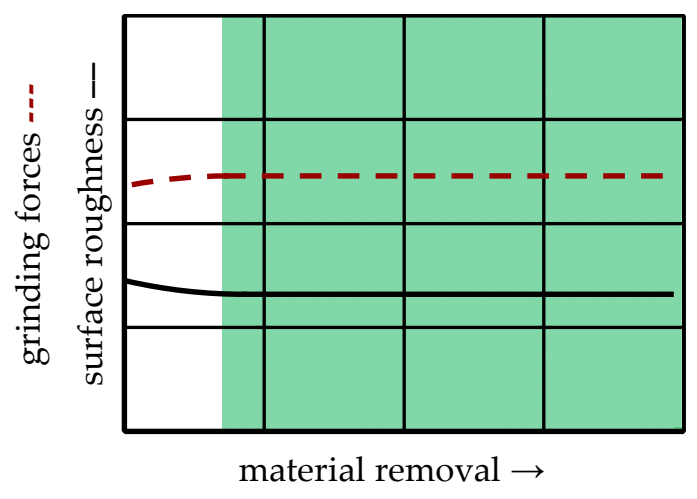

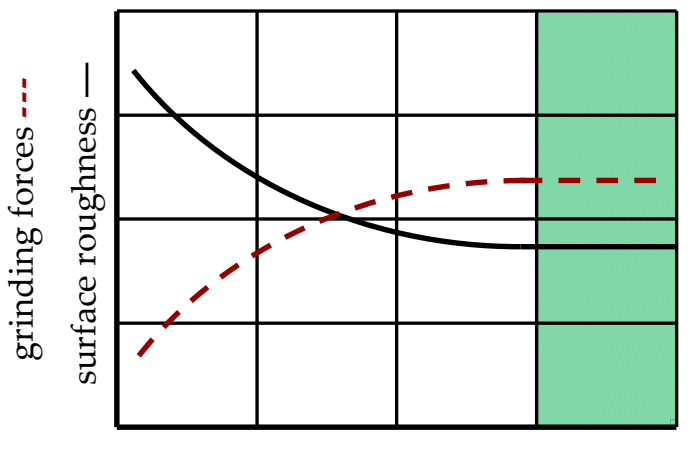

material removal $\rightarrow$

(b) Over sharpened

$\square \quad$ Grinding-in Phase

$\square$ Stationary process behavior

(c) Optimized sharpening process

Figure 1. Grinding behavior of differently sharpened grinding wheels [7].

Only a few publications are concerned with CNC-controlled sharpening processes. JACOBS [8] analyzed the automated sharpening process with ceramic- and resin-bonded CBN grinding wheels. He found that the microgeometry of a grinding wheel can be influenced by the parameters sharpening block width $l_{\mathrm{Sb}}$ and material removal $\mathrm{V}_{\mathrm{Sb}}$. The surface roughness increases asymptotically with increasing material removal $\mathrm{V}_{\mathrm{Sb}}$ until a stationary value is reached. The increase in the sharpening block width $1_{\mathrm{Sb}}$ also resulted in an increase in roughness. The grain break-out mechanics of resin-bonded grinding wheels sharpened with corundum blocks was studied by SCHLEICH [9]. He developed a model for the sharpening process to adjust the desired CBN grain protrusion. The sharpening process of ceramic-bonded grinding wheels was studied by STUFF [10]. He developed sharpening strategies through experimental studies to achieve a stationary grinding behavior. Studies on the sharpening process of metal-bonded grinding wheels are performed with electrophysical and electrochemical processes due to their electrical conductivity [11-15]. HÜBERT [16] investigated the intermittent sharpening process of resinbonded diamond grinding wheels. He determined that the results of the sharpening process 
were dependent on the grinding wheel grain size. Furthermore, an increase in the dressing volume was detected for a higher specific material removal rate in sharpening $\mathrm{Q}^{\prime} \mathrm{Sb}$.

To date, only a small number of publications on the CNC-controlled sharpening process of diamond grinding wheels are available. This paper presents new findings concerning the CNC-controlled block sharpening process of hybrid-bonded diamond grinding wheels. In this case, the hybrid bond represents a combination of metal and resin bond. For this purpose, extensive experiments were performed to identify the significant sharpening parameters and to establish a functional relationship between the sharpening parameters and the resulting topography characteristics, the sharpening result. Based on the experimental results, an empirical regression model was developed.

\section{Influence of the Sharpening Parameters on the Grinding Wheel Topography}

Extensive sharpening experiments were carried out to identify the significant sharpening parameters influencing the process. The experiments were performed on the CNC tool grinding machine WU 305 MICRO from Alfred H. Schütte, Köln, Germany. As possible influencing parameters, the grain size of the sharpening block $\mathrm{d}_{\mathrm{kSb}}$, the sharpening block width $1_{\mathrm{sb}}$, the area-related material removal in sharpening $\mathrm{V}^{\prime \prime}{ }_{\mathrm{Sb}}$, the area-related material removal rate in sharpening $\mathrm{Q}^{\prime \prime} \mathrm{sb}$ and the grinding wheel circumferential speed $\mathrm{v}_{\mathrm{sSb}}$ were considered. In addition, the tests were carried out with two grinding wheel specifications, which differ in grain size $d_{k}$. The hybrid-bonded grinding wheels with specifications 1A1 D33 C100 and 1A1 D54 C100 from Saint-Gobain Diamantwerkzeuge GmbH Norderstedt, Germany, had a grinding wheel diameter of $d_{s}=100 \mathrm{~mm}$. In order to be able to transfer the knowledge gained to other grinding wheel dimensions, the area-related material removal in sharpening $\mathrm{V}^{\prime \prime}{ }_{\mathrm{sb}}$ and the area-related material removal rate in sharpening $\mathrm{Q}^{\prime \prime}{ }_{\mathrm{sb}}$ were placed in relation to the lateral surface of the grinding wheel. In the first step, the parameters were varied by two values, as shown in Table 1 . The sharpening experiments were performed with the block sharpening method.

Table 1. Investigated sharpening parameters.

\begin{tabular}{cccccc}
\hline $\mathbf{d}_{\mathbf{k}}$ & $\mathbf{d}_{\mathbf{k S b}}$ & $\mathbf{l}_{\mathbf{S b}}$ & $\mathbf{V}^{\prime \prime} \mathbf{S b}$ & $\mathbf{Q}^{\prime \prime} \mathbf{S b}$ & $\mathbf{v}_{\mathbf{s S b}}$ \\
\hline$\mu \mathrm{m}$ & $\mathrm{mesh}$ & $\mathrm{mm}$ & $\mathrm{mm}^{3} / \mathrm{mm}^{2}$ & $\mathrm{~mm}^{3} /\left(\mathrm{mm}^{2} \cdot \mathrm{s}\right)$ & $\mathrm{m} / \mathrm{s}$ \\
\hline 33 & 180 & 25.0 & 0.159 & 0.0159 & 10 \\
54 & 220 & 12.5 & 0.382 & 0.0318 & 17 \\
\hline
\end{tabular}

In order to evaluate the influence of the investigated sharpening parameters, the grinding wheels were prepared by a profiling process using silicon carbide (SiC) dressing rolls from Winterthur Technology $\mathrm{GmbH}$, Reutlingen, Germany, in order to achieve reproducible and smooth initial surface conditions. The profiling was carried out with a depth of dressing cut of $\mathrm{a}_{\mathrm{ed}}=4 \mu \mathrm{m}$ at a total depth of of dressing cut $\mathrm{a}_{\mathrm{ed}, \mathrm{ges}}=800 \mu \mathrm{m}$, a dressing feed rate of $v_{f d}=1500 \mathrm{~mm} / \mathrm{min}$, a ratio of dressing speeds $q_{d}=-1$ and a grinding wheel circumferential speed during dressing of $\mathrm{v}_{\mathrm{sd}}=17 \mathrm{~m} / \mathrm{s}$. The sharpening blocks with corundum grains from Saint-Gobain Diamantwerkzeuge GmbH, Norderstedt, Germany, were soaked in cooling lubricant before the experiments. During the sharpening process, the grinding wheel was radially moved to the sharpening block without the supply of cooling lubricant. For the analysis of the CNC-controlled block sharpening process, imprints of a section of the grinding wheel were captured and optically measured. The imprints were made by using the dental imprint material Panasil ${ }^{\circledR}$ contact plus X-Light of Kettenbach GmbH \& Co. KG, Eschenburg, Germany. Subsequently, an optical surface measurement was carried out with a digital light microscope of the type VHX-5000 from Keyence Deutschland GmbH, Neu-Isenburg, Germany. Finally, the topography characteristics of the grinding wheels were determined according to DIN EN ISO 25178 [17] using a developed algorithm in MATLAB $^{\circledR}$ from MathWorks, Natick, MA, USA. Figure 2 shows the experimental procedure and the subsequent topography analysis. To ensure the 
reproducibility of the experiments statistically, each parameter combination was carried out three times.

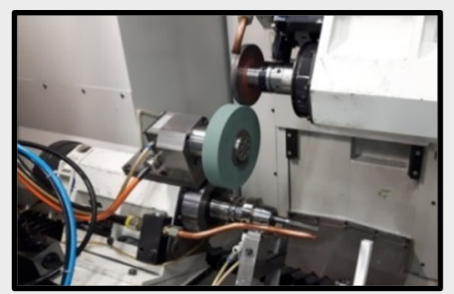

Profiling

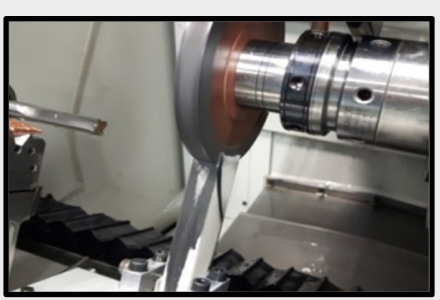

Sharpening

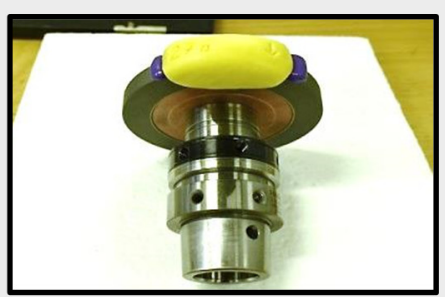

Create imprints

Experimental procedure

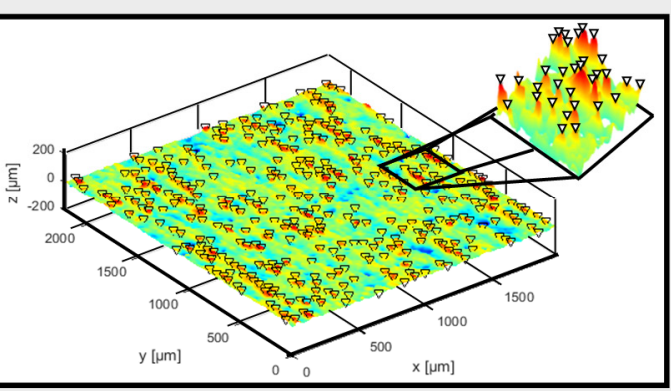

Identifying the cutting grains

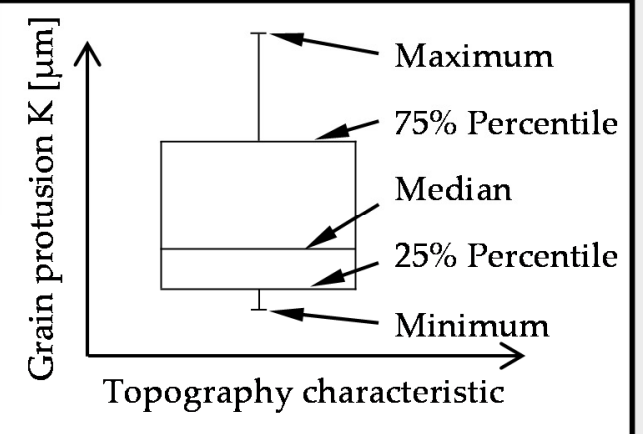

Evaluating the grain protrusion $\mathrm{K}$

Topography analysis

Figure 2. Experimental procedure and topography analysis.

After determining the topography characteristics, a significance analysis was performed to evaluate the sharpening parameters and identify the significant sharpening parameters. Therefore, a statistical evaluation tool was developed to establish a functional relationship between the input variables (sharpening parameters) and output variables (topography characteristics). To evaluate the accuracy of the established models and the influence of the sharpening parameters, the stochastic characteristics, the coefficient of determination $\mathrm{R}^{2}$ and the $p$-value were determined. The coefficient of determination $\mathrm{R}^{2}$ indicates how suitable the models are for explaining the total variation of the determined topography characteristics. It varies between $0 \%$ (poor model accuracy) and 100\% (good model accuracy). The $p$-value describes the probability that the null hypothesis is true, where the null hypothesis is a general statement that declares there is no relationship between the input and output variable. If the $p$-value of an input variable is below the significance level of $5 \%$, then it can be assumed to have a significant influence on the output variable [18,19].

Figure 3 shows the result of the significance analysis for the topography characteristics, the reduced peak height Spk and the mean arithmetic height Sa. The standardized coefficients describe the linear influence of the respective sharpening parameter on the topography characteristic. Different model accuracy results were achieved for the analyzed topography characteristics. Considering the results of the grinding wheel with the grain size D33, it becomes clear that the established model to describe the reduced peak high Spk with a coefficient of determination $\mathrm{R}^{2}=22.85 \%$ does not adequately reflect the actual measurements. Additionally, the $p$-values of the investigated sharpening parameters were clearly above the significance level, so it can be assumed that the investigated parameters have no significant influence on the reduced peak height Spk of the grinding wheel with the grain size D33. On the other hand, the quality for describing the mean arithmetic 
height Sa was $\mathrm{R}^{2}=69.90 \%$. The $p$-values for the grain size of the sharpening block $\mathrm{d}_{\mathrm{kSb}}$, the sharpening block width $1_{\mathrm{Sb}}$, the area-related material removal rate in sharpening $\mathrm{Q}^{\prime \prime} \mathrm{Sb}$ and the grinding wheel circumferential speed $\mathrm{v}_{\mathrm{sSb}}$ were below the significance level of $5 \%$ and thus significantly influenced the topography characteristic Sa. However, the results of the grinding wheel with the grain size D54 show a high coefficient of determination $R^{2}=74.86 \%$ for the reduced peak height Spk. The area-related material removal in sharpening $\mathrm{V}^{\prime \prime} \mathrm{Sb}$, the sharpening block width $\mathrm{l}_{\mathrm{Sb}}$ and the grain size of the sharpening block $\mathrm{d}_{\mathrm{kSb}}$ are the sharpening parameters that influence the topography characteristic Spk significantly. In contrast, the mean arithmetic height $\mathrm{Sa}$ is not influenced by the sharpening parameters.

$\square$ Standardized coefficient
p-value
-----. Significance level

\begin{tabular}{|c|c|c|c|c|}
\hline \multirow{2}{*}{$\begin{array}{c}\text { Coefficient } \\
\text { of deter- } \\
\text { mination }\end{array}$} & \multicolumn{2}{|c|}{ D33 } & \multicolumn{2}{c|}{ D54 } \\
\cline { 2 - 5 } & Spk & Sa & Spk & Sa \\
\hline $\mathrm{R}^{2}[\%]$ & 22.85 & 69.90 & 74.86 & 22.70 \\
\hline
\end{tabular}

Grinding wheel D33
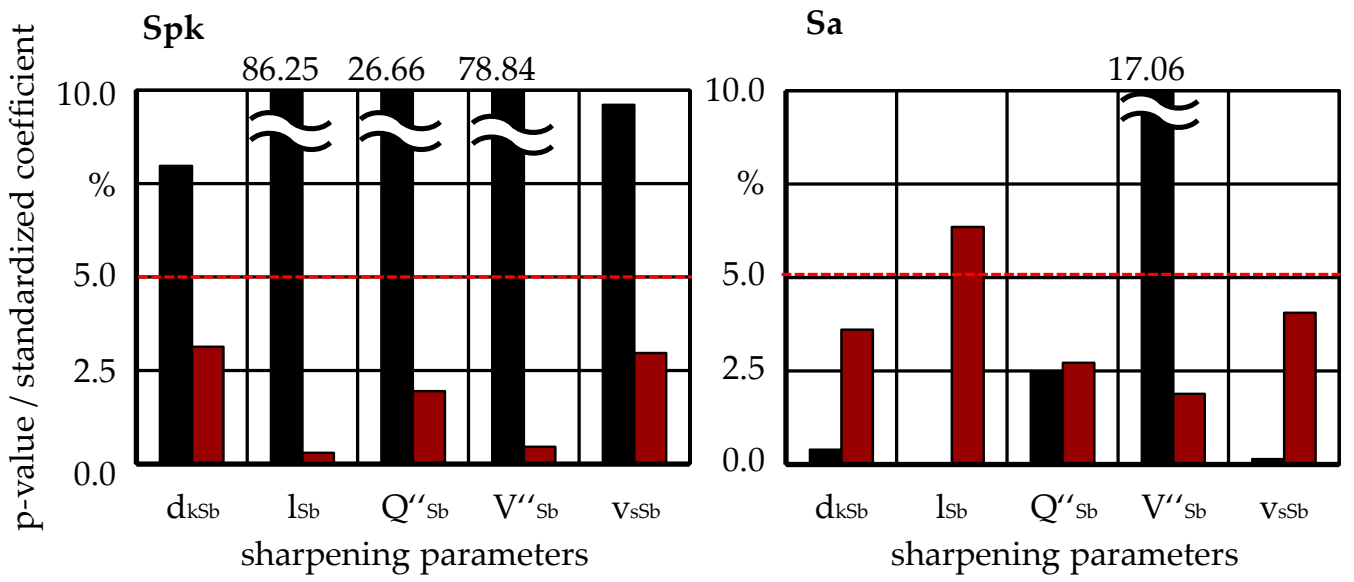

Grinding wheel D54

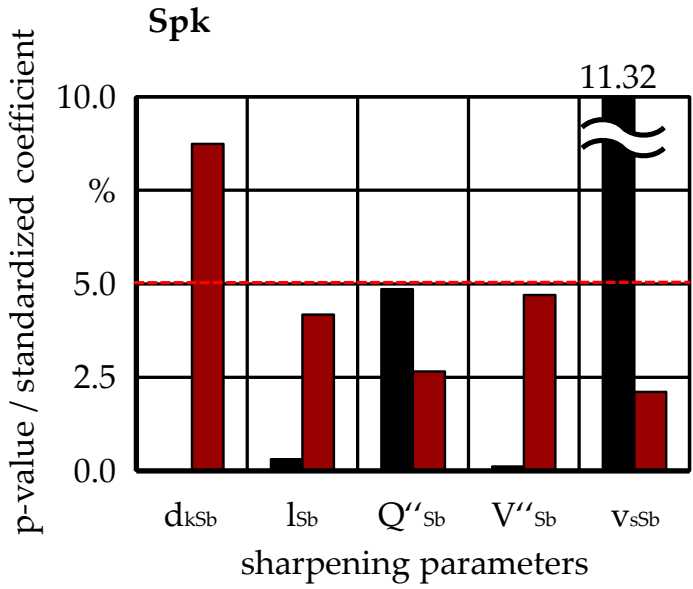

Sa

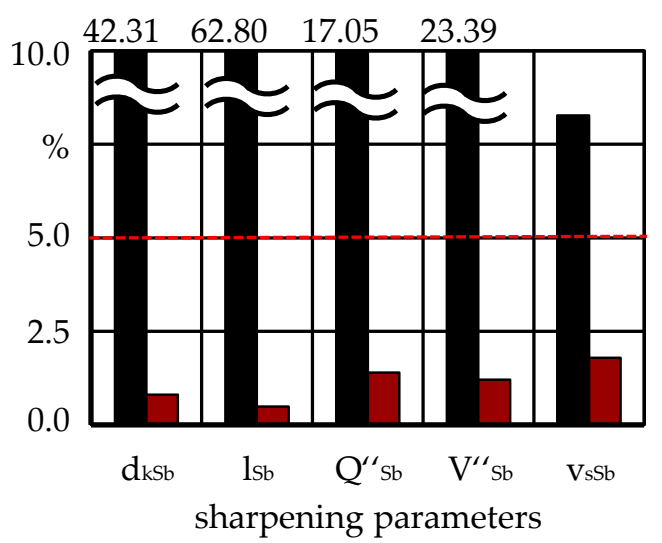

Figure 3. Significance analysis for the topography characteristics, the reduced peak height Spk and the mean arithmetic height Sa.

The results of the investigated grinding wheels are different and show that the sharpening parameters affect the grinding wheel topography differently. Figure 4 shows the reduced peak height Spk and the mean arithmetic height Sa for the respective sharpening experiments. The parameter of the experiments can be found in the Appendix A, Table A1. The grinding wheel topography after profiling is highlighted with a green bar and describes the initial state of the grinding wheels before the sharpening process. It becomes clear that 
the sharpening process results in a significant increase in the reduced peak height Spk for both grinding wheels D33 and D54.

\section{○ D33 ○ D54}

Unsharpened / After profiling
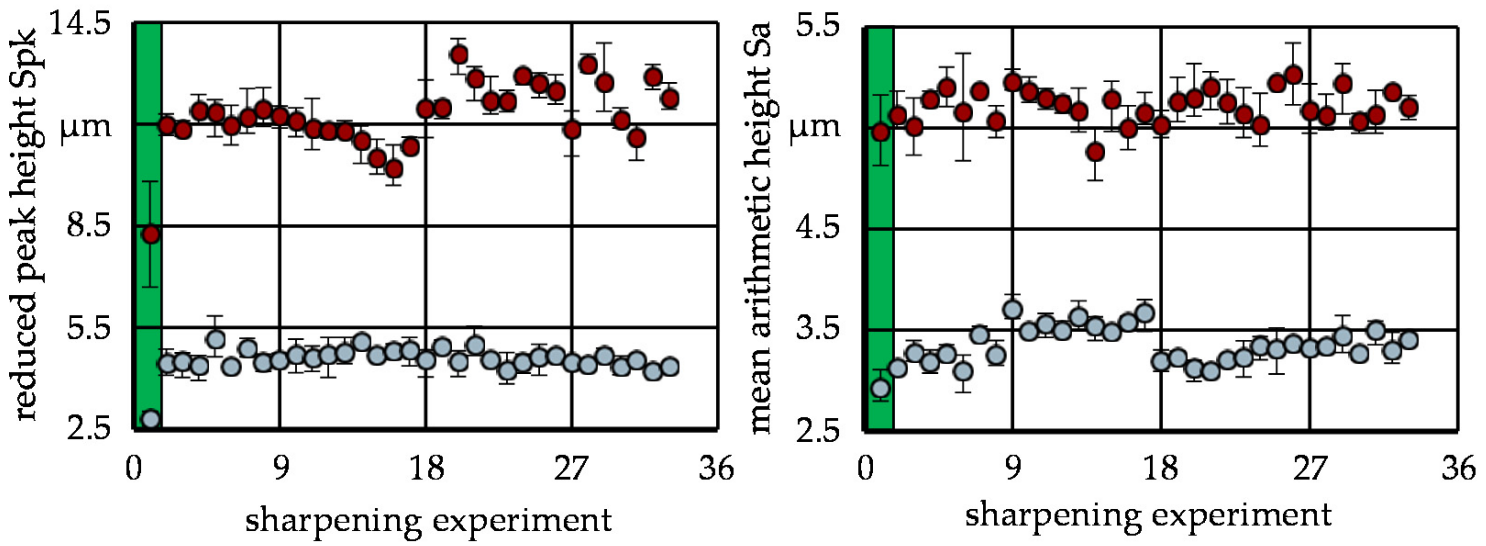

Figure 4. Topography characteristics of the sharpening experiments.

The increase is due to an effective resetting of the grinding wheel bond after profiling. During the sharpening process, a suspension forms between the grinding wheel and the sharpening block, which is mainly responsible for the resetting of the bond during the sharpening process, as shown in Figure 5. The suspension is formed by the cooling lubricant and the corundum grains of the sharpening block, which are split during the process.

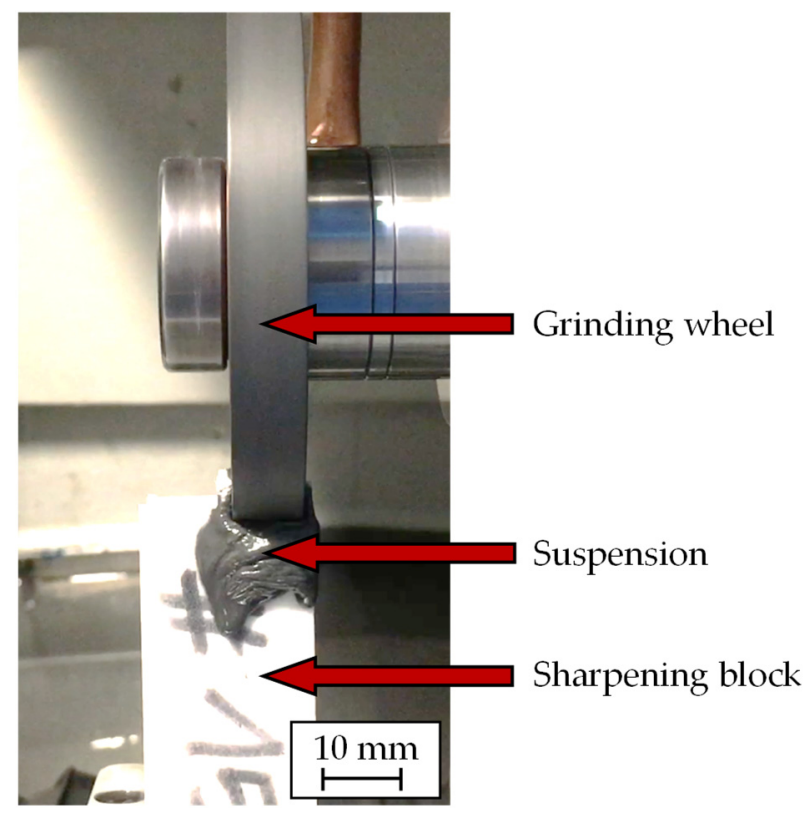

Figure 5. Block sharpening process.

For the grinding wheel with the grain size D33, the reduced peak height Spk differed only slightly between the sharpening experiments. It can be assumed that the investigated sharpening parameters lead to an over-sharpened grinding wheel D33, and thus a change in the parameters has no significant influence on the topography characteristic Spk. However, significant differences can be seen between the experiments for the grinding wheel with the grain size D54. Here, the sharpening parameters clearly affect the topography characteristic Spk. The differences in the results are due to the grinding wheel specification, in this case 
the grinding wheel grain size. For both grinding wheels, the mean arithmetic height Sa is influenced by the variation of the sharpening parameters. The variations for the grinding wheel with a grain size of D54 are weak compared to the topography characteristic Spk. The findings are also reflected in the stochastic analysis.

The results of the significance analysis show that the grinding wheel specification has a decisive effect on which topography characteristics are influenced by the sharpening parameters. It could be determined that both investigated grinding wheels were mainly influenced by the sharpening width $l_{\mathrm{Sb}}$ and the grain size of the sharpening block $\mathrm{d}_{\mathrm{kSb}}$. In further investigations, the influence of the area-related material removal in sharpening $\mathrm{V}^{\prime \prime} \mathrm{Sb}$ was studied in more detail. The result is shown in Figure 6. It becomes clear that there is a non-linear relationship between the area-related material removal in sharpening $\mathrm{V}^{\prime \prime} \mathrm{Sb}$ and the topography characteristics, reduced peak height Spk and mean arithmetic height Sa. The topography characteristics increased with a higher sharpening volume until a steady-state behavior was achieved. The stationary behavior was reached earlier by the grinding wheel with a grain size of D33. The investigation has shown that the area-related material removal in sharpening $\mathrm{V}^{\prime \prime} \mathrm{Sb}$ also significantly influences the grinding wheel topography.

Tool:

Sharpening block: $220 \#$

Grinding wheel: 0 D54

O D33
Sharpening parameter:

$$
\begin{array}{lll}
\mathrm{lsb}_{\mathrm{sb}}=25 & \mathrm{~mm} \\
\mathrm{Q}^{\prime \prime} \mathrm{sb}= & 0.0159 & \mathrm{~mm}^{3} /\left(\mathrm{mm}^{2} \cdot \mathrm{s}\right) \\
\mathrm{V}_{\mathrm{sSb}}= & 10 & \mathrm{~m} / \mathrm{s}
\end{array}
$$
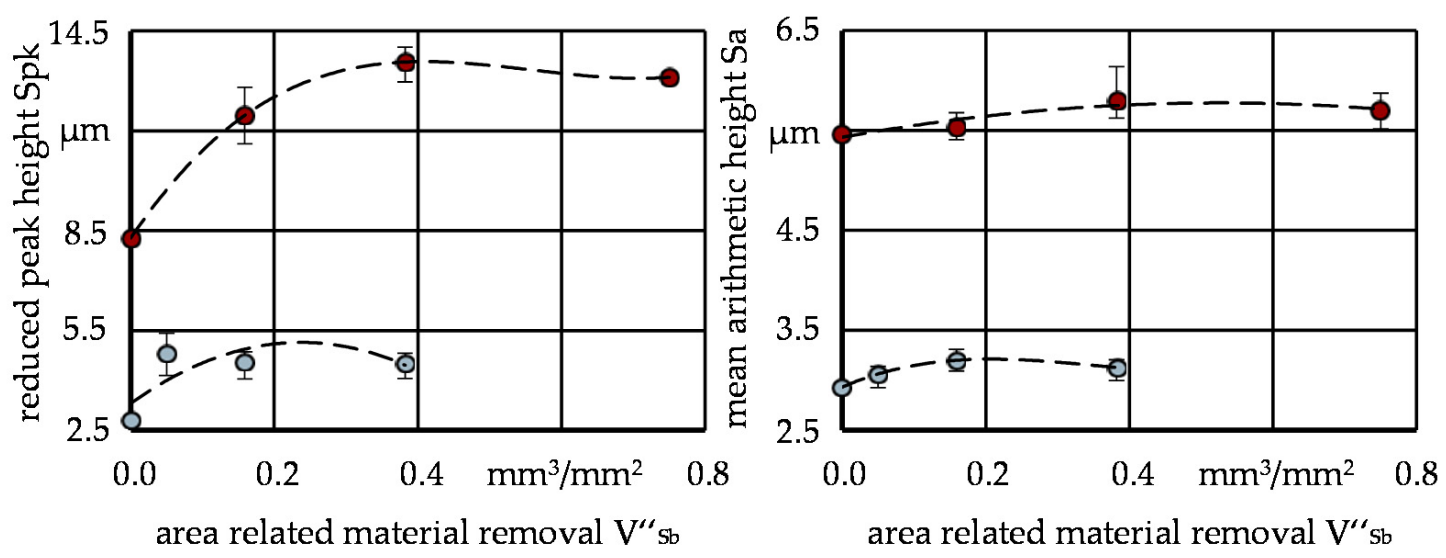

Figure 6. Influence of the area-related material removal in sharpening $\mathrm{V}^{\prime \prime} \mathrm{sb}$.

The main influencing parameters could be determined by the experimental analysis. However, the results of the significance analysis also reveal that the grinding wheel specification effectively define which sharpening parameters influence certain topography characteristics. Nevertheless, the study clearly showed that it is possible to find correlations between sharpening parameters and the resulting grinding wheel topography.

\section{Influence of the Sharpening Parameters on the Grinding Wheel Topography}

After identifying the significant sharpening parameters, the experiments were extended to evaluate the influence on the grinding wheel topography and to generate the necessary data for the development of an empiric process model. The extension was carried out by increasing the parameter variation from two to four, as shown in Table 2. A full factorial variation of the parameters was carried out. 
Table 2. Significant sharpening parameters.

\begin{tabular}{cccc}
\hline $\mathbf{d}_{\mathbf{k S b}}$ & $\mathbf{d}_{\mathbf{k S b}}$ & $\mathbf{l}_{\mathbf{S b}}$ & $\mathbf{V}^{\mathbf{\prime}} \mathbf{S b}$ \\
\hline mesh & $\mu \mathrm{m}$ & $\mathrm{mm}$ & $\mathrm{mm}^{3} / \mathrm{mm}^{2}$ \\
\hline 150 & 80 & 9.0 & 0.080 \\
180 & 70 & 12.5 & 0.159 \\
220 & 58 & 18.0 & 0.382 \\
320 & 33 & 25.0 & 0.600 \\
\hline
\end{tabular}

The area-related material removal rate in sharpening and the grinding wheel circumferential speed were kept constant with $\mathrm{Q}^{\prime \prime} \mathrm{Sb}=0.0159 \mathrm{~mm}^{3} /\left(\mathrm{mm}^{2} \cdot \mathrm{s}\right)$ and $\mathrm{v}_{\mathrm{sSb}}=10 \mathrm{~m} / \mathrm{s}$. The experiments were performed with the grinding wheel grain size D54. In the following, the influence of the significant sharpening parameters on the grinding wheel topography is evaluated. For this, the average value of 16 experiments was determined by keeping one parameter constant. Thereafter, the percentage deviation of the topography characteristics from the initial profiled state was considered. The topography characteristics after the profiling process are listed in Table 3.

Table 3. Topography characteristics in the initial profiled state.

\begin{tabular}{cccccc}
\hline Spk & Svk & Sk & Sa & $\mathbf{N}_{\text {stat }}$ & K \\
\hline$\mu \mathrm{m}$ & $\mu \mathrm{m}$ & $\mu \mathrm{m}$ & $\mu \mathrm{m}$ & $1 / \mathrm{mm}^{2}$ & $\mu \mathrm{m}$ \\
\hline 8.28 & 7.08 & 16.10 & 5.47 & 80.62 & 15.29 \\
\hline
\end{tabular}

\subsection{Influence of the Grain Size of the Sharpening Block $d_{k S b}$}

Figure 7 shows the influence of the grain size of the sharpening block $d_{k S b}$ on the topography characteristics reduced peak height Spk, reduced valley height Svk, core roughness Sk and static number of cutting edges $\mathrm{N}_{\text {stat }}$. There is a great influence of the grain size of the sharpening block on the topography characteristics Spk and Svk. Sharpening blocks with a smaller grain size led to an increase of the Spk value. The change in the reduced peak height Spk nearly reached 38\%. A small increase in the Svk value was observed when sharpening with a grain size of 150 mesh. Then, a steady drop with an increasing mesh value could be seen. The changes in the topography values $\mathrm{N}_{\text {stat }}$ and Sk were less than $9 \%$ for the mesh sizes of 150 to 220 . In contrast, sharpening with a mesh size of 320 led to an increase over $20 \%$. Considering the topography characteristic, it can be assumed that the sharpening process is more efficient with a finer grain size of the sharpening block $\mathrm{d}_{\mathrm{kSb}}$.

Additional flute grinding processes were carried out to investigate the grinding behavior. For this purpose, untwisted flutes were ground on cemented carbide blanks with a diameter of $\mathrm{d}_{\mathrm{w}}=12 \mathrm{~mm}$ of the type EMT100 from EXTRAMET AG, EXTRAMET AG, Plaffein, Switzerland. The tests were carried out in the sharpened and unsharpened state of the grinding wheel. To evaluate the process behavior, the process normal force $F_{n}$ and tangential force $F_{t}$ were considered, as shown in Figure 8. The grinding forces with the unsharpened grinding wheel after the profiling process are highlighted with a green bar. For small mesh sizes of the sharpening blocks $\mathrm{d}_{\mathrm{kSb}}$, the grinding forces were significantly lower than in the profiled state. The grinding forces increased with increasing mesh size of the sharpening block, reaching the value of the profiled grinding wheel by sharpening with $d_{\mathrm{kSb}}=320$ mesh. 

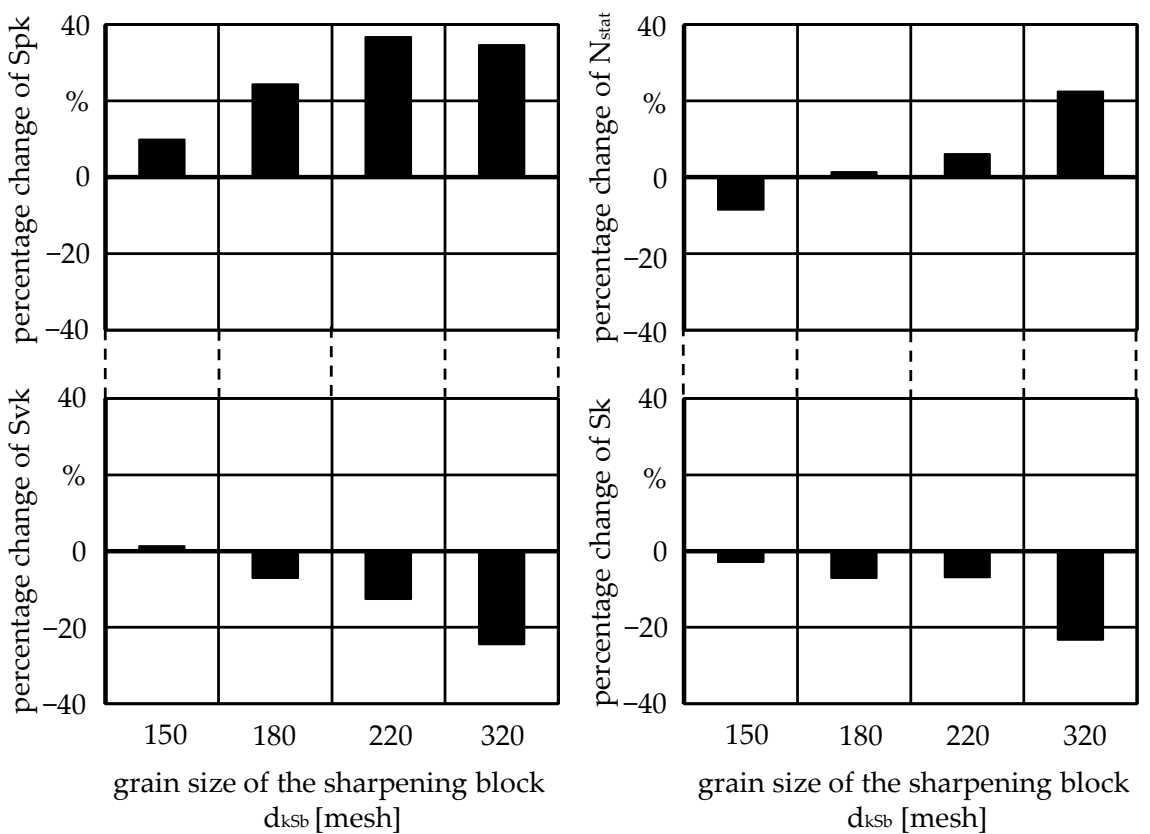

Figure 7. Influence of the grain size of the sharpening block $d_{k S b}$ on the topography characteristics.

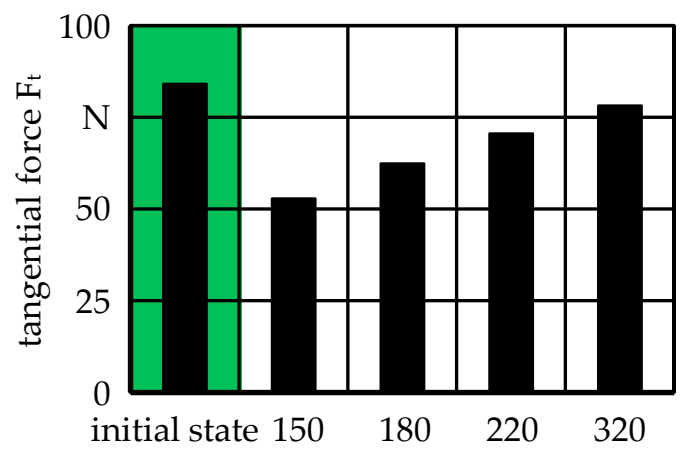

grain size of the sharpening block $d_{k s b}[$ mesh]

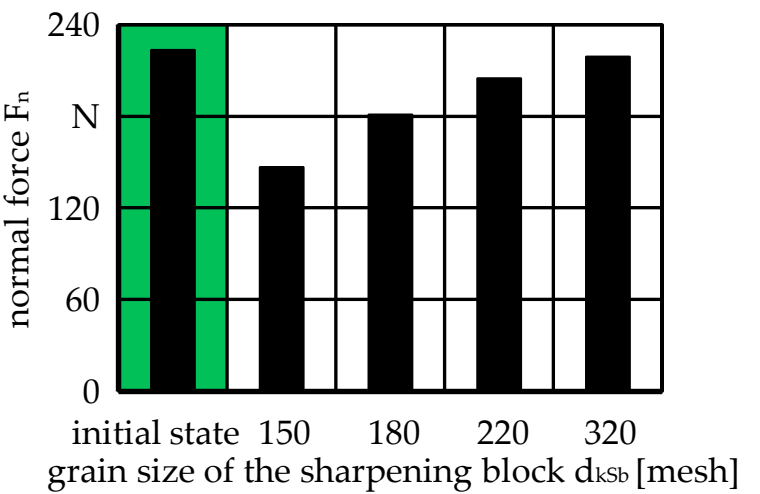

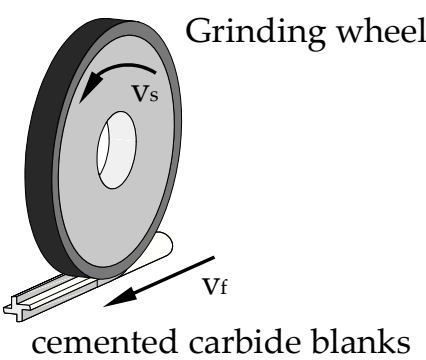

Tool:

1A1 D54

Hybrid bond

Workpiece material:

Cemented carbide EMT 100

$6 \% \mathrm{Co}$, fine grain

Grinding parameter:

$\begin{array}{rll}\mathrm{Vs} & =17 & \mathrm{~m} / \mathrm{s} \\ \mathrm{Vf} & =70 \mathrm{~mm} / \mathrm{min}\end{array}$

Up grinding

Groove geometry:

$\mathrm{d}_{\mathrm{w}}=12 \mathrm{~mm}$

$\mathrm{t}_{\mathrm{n}}=2.5 \mathrm{~mm}$

$\lambda=0$ ०

$\lambda_{\mathrm{v}}=2{ }^{\circ}$

Figure 8. Influence of the grain size of the sharpening block $\mathrm{d}_{\mathrm{kSb}}$ on the grinding forces.

The analysis of the topography characteristics and grinding forces showed that the sharpening process is significantly influenced by the grain size of the sharpening block $\mathrm{d}_{\mathrm{kSb}}$ and thus influences the grinding behavior. Coarse sharpening block grains lead to a rough grinding wheel topography, which results in low grinding forces. Furthermore, a positive correlation between the grinding forces and the topography characteristics Spk and $\mathrm{N}_{\text {stat }}$ were observed, which is an unexpected result, since low grinding forces are assumed to have highly exposed cutting edges. The contradiction makes it clear that the evaluation 
of individual topography characteristics cannot be used to predict the sharpness of the grinding wheel with sufficient accuracy.

The observed relationships can be explained by the higher momentum, which is imposed on the bond by the coarse grains. In the case of small grain size of the sharpening block, clogging the chip space is possible, which leads to a decrease in the grinding wheel roughness. The actual sharpening process was hindered by the clogging of the grinding wheel. In addition, the existing pores were closed, which was reflected by a decrease in the topographic characteristics Svk and Sk. To verify the assumptions, additional topography measurements were carried out directly on the grinding wheel. For this purpose, the grinding wheel was measured after sharpening with the sharpening stone $d_{k S b}=150$ mesh and $\mathrm{d}_{\mathrm{kSb}}=320$ mesh. The profile height of the measured grinding wheel topography after the respective sharpening process is shown in Figure 9. Based on the measured profile height, it becomes clear that sharpening with $\mathrm{d}_{\mathrm{kSb}}=150$ mesh leads to a rough topography and thus sets back the bond more effectively.

Mesh 150

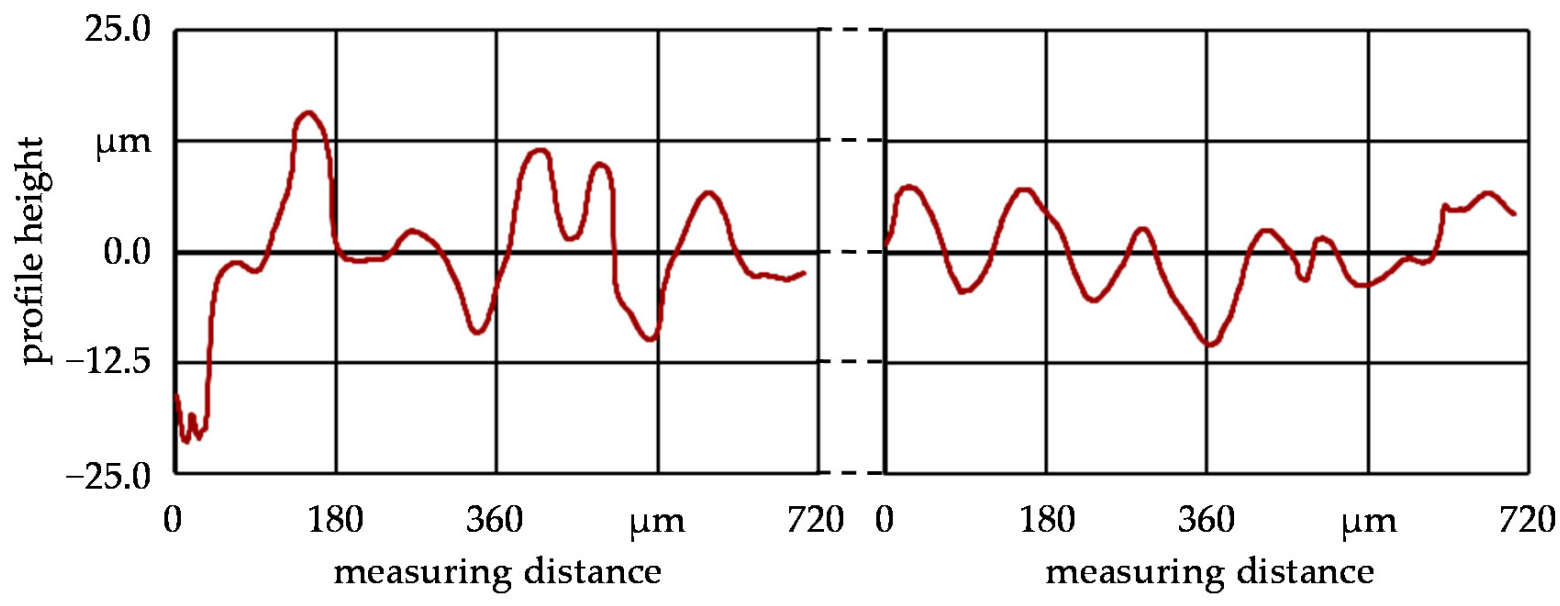

Figure 9. Influence of the grain size of the sharpening block $d_{k S b}$ on the profile height.

\subsection{Influence of the Sharpening Block Width $l_{S b}$}

Figure 10 illustrates the influence of the sharpening block width $1_{\mathrm{Sb}}$ on the grinding wheel topography. The percentage change of the topography characteristics was almost constant over the variation of the sharpening block width $\mathrm{l}_{\mathrm{Sb}}$. For the value $\mathrm{Sk}$, a slightly steady decline with increasing sharpening block width $l_{S b}$ was observed. However, there was no significant influence of the sharpening block width $1_{\mathrm{Sb}}$ on the grinding wheel topography.

The grinding forces depending on the sharpening block width $l_{\mathrm{Sb}}$ are shown in Figure 11. After the sharpening process, the grinding forces were lower than in the initial profiled state and were almost on a constant level. The influence of the sharpening block width $1_{\mathrm{Sb}}$ was smaller compared to the other two investigated sharpening parameters. Interactions between the sharpening parameters should be considered separately and be taken into account in the development of the process model.

\subsection{Influence of the Area-Related Material Removal in Sharpening $V^{\prime \prime} s b$}

The influence of the area-related material removal in sharpening $\mathrm{V}_{\mathrm{Sb}}$ on the grinding wheel topography can be seen in Figure 12. The material removal had a significant influence on the Spk value, which increased with increasing volume. A steady decline could be obtained for the reduced valley height Svk. The influence on the static number of cutting edges $\mathrm{N}_{\text {stat }}$ was small. The observations can be explained by the fact that the resetting of the bond material increased when increasing the area-related material removal in sharpening $\mathrm{V}^{\prime \prime} \mathrm{Sb}$, which results in smaller pores and thus leads to a reduction in the Svk value. At 
the same time, the grain protrusion increased, and new subsequent grains were exposed, which led to an increase in the reduced peak height Spk.
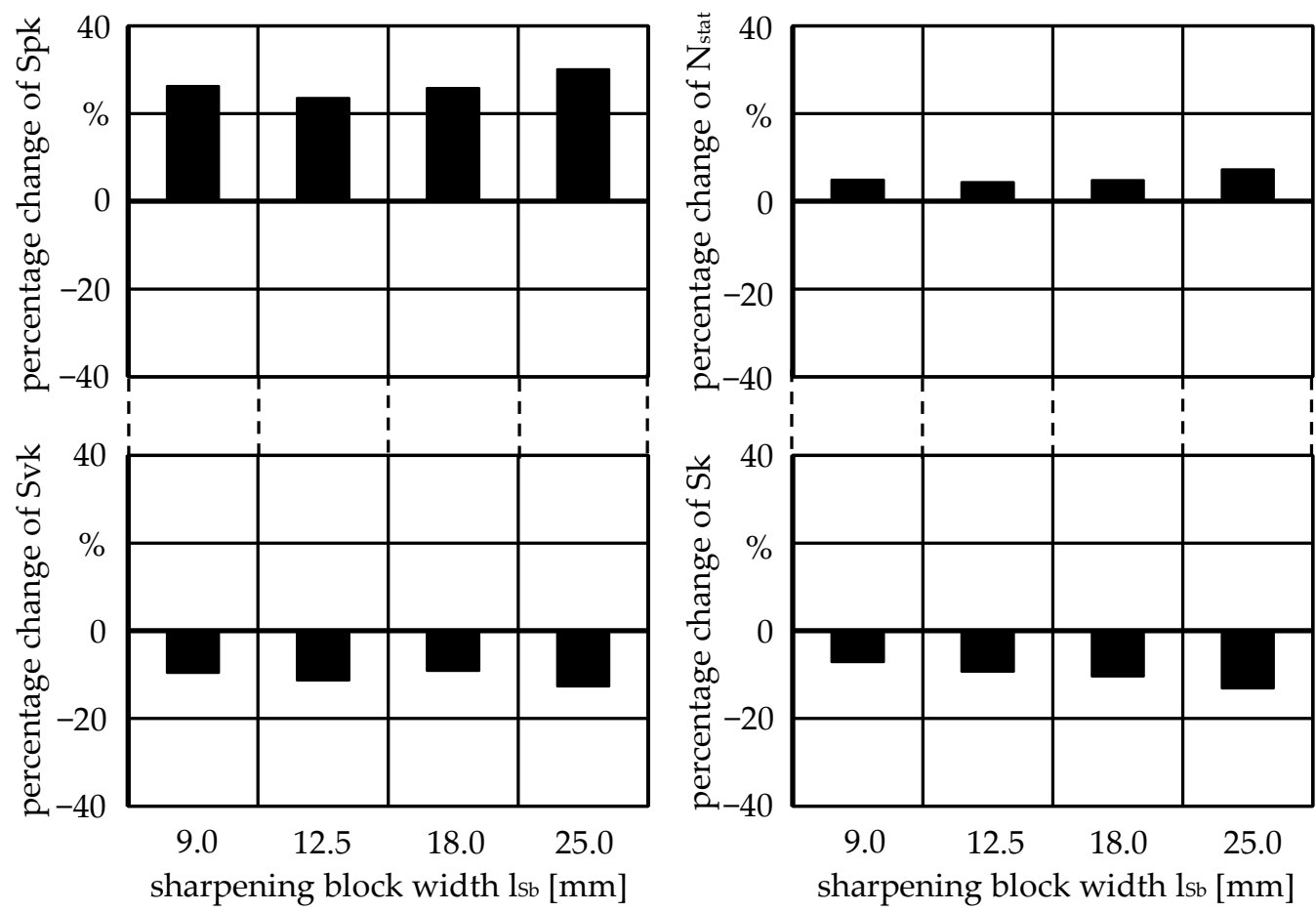

Figure 10. Influence of the sharpening block width $1_{\mathrm{Sb}}$ on the topography characteristics.
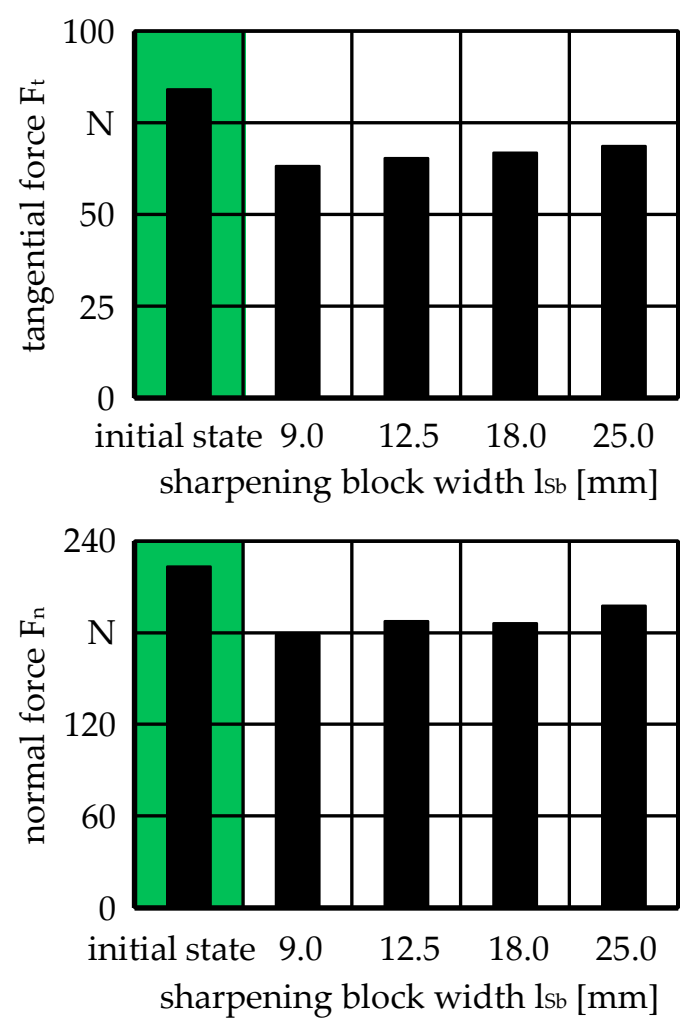

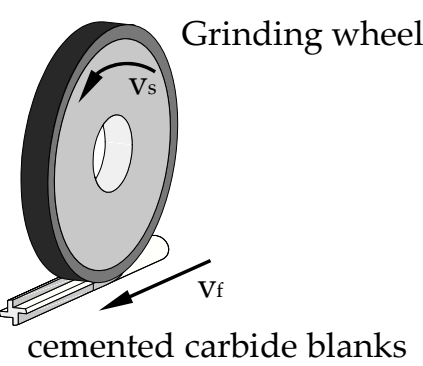

Tool:

1A1 D54

Hybrid bond

Workpiece material:

Cemented carbide EMT 100

$6 \% \mathrm{Co}$, fine grain

Grinding parameter:

$\mathrm{Vs}_{\mathrm{s}}=17 \mathrm{~m} / \mathrm{s}$

$\mathrm{V}_{\mathrm{f}}=70 \mathrm{~mm} / \mathrm{min}$

Up grinding

Groove geometry:

$\mathrm{d}_{\mathrm{w}}=12 \mathrm{~mm}$

$\mathrm{tn}_{\lambda}=2.5 \mathrm{~mm}$

$\lambda=0 \quad 0$

$\lambda_{\mathrm{v}}=2 \circ$

Figure 11. Influence of the sharpening block width $l_{\mathrm{Sb}}$ on the grinding forces. 


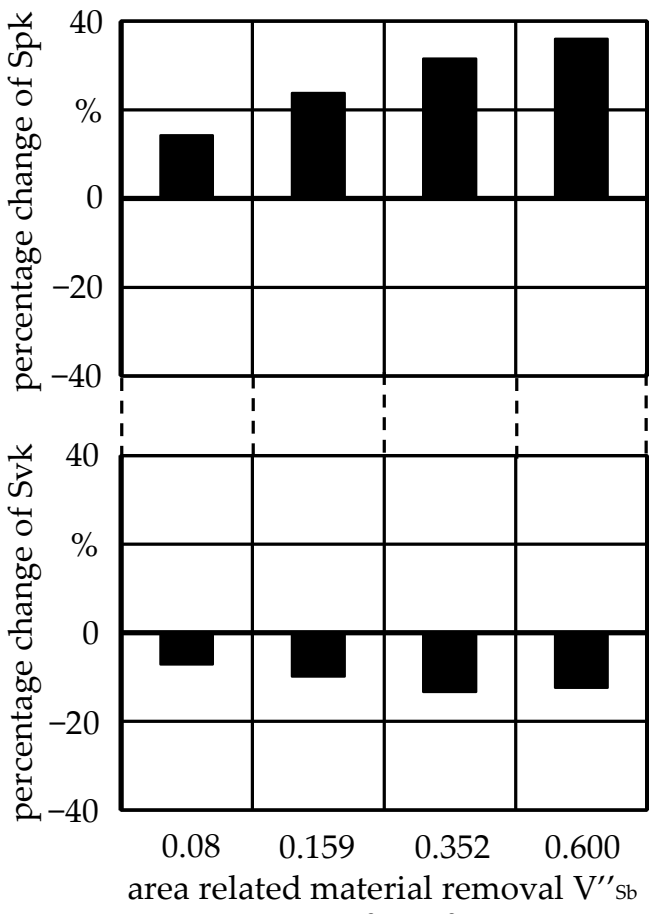

$\left[\mathrm{mm}^{3} / \mathrm{mm}^{2}\right]$

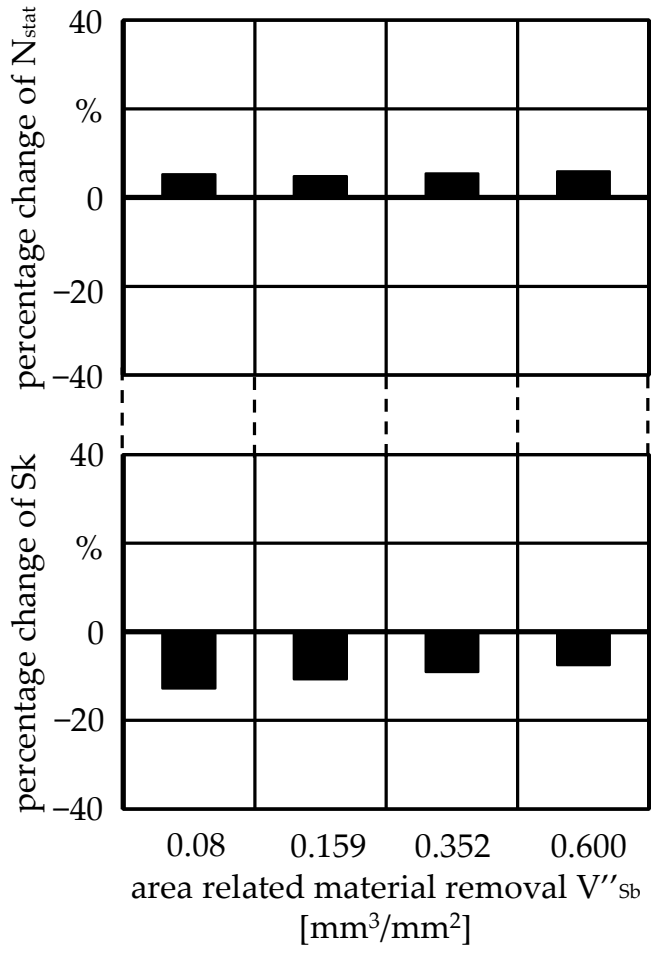

Figure 12. Influence of the area-related material removal V"sb on the topography characteristics.

Figure 13 illustrates the grinding forces depending on the area-related material removal in sharpening $\mathrm{V}^{\prime \prime} \mathrm{sb}$. The resetting of the bond material results in a rough grinding wheel topography and thus in a reduction in the grinding forces.

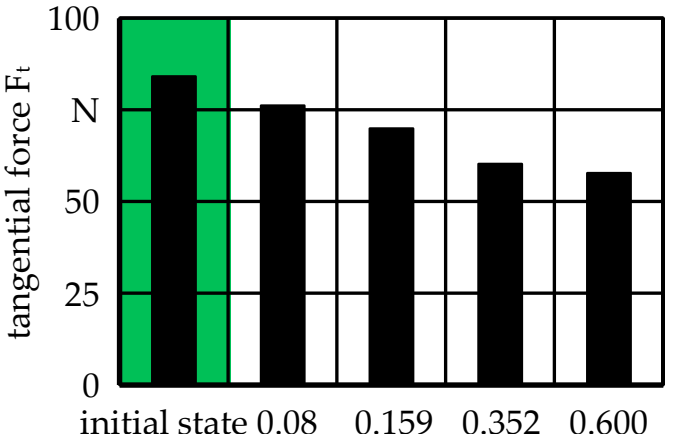

area related material removal $\mathrm{V}^{\prime \prime} \mathrm{sb}\left[\mathrm{mm}^{3} / \mathrm{mm}^{2}\right]$

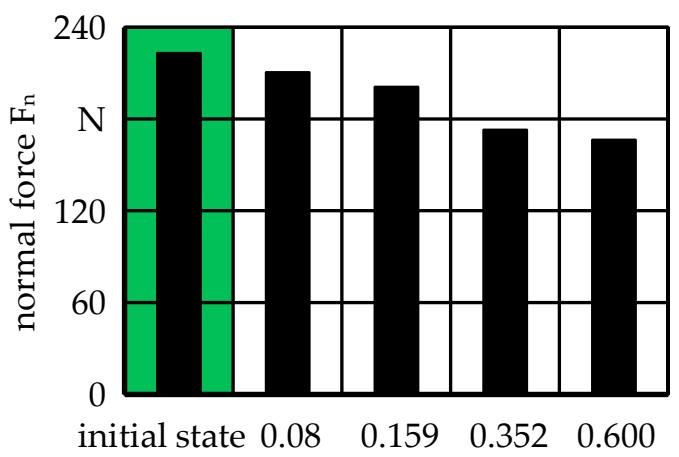

area related material removal V"sb $\left[\mathrm{mm}^{3} / \mathrm{mm}^{2}\right]$

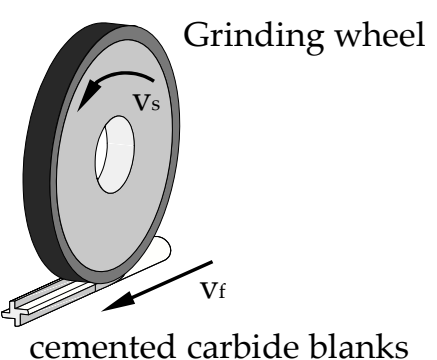

Tool:

1A1 D54

Hybrid bond

Workpiece material:

Cemented carbide EMT 100

$6 \% \mathrm{Co}$, fine grain

Grinding parameter:

$\mathrm{vs}_{\mathrm{s}}=17 \mathrm{~m} / \mathrm{s}$

$\mathrm{Vf}_{\mathrm{f}}=70 \mathrm{~mm} / \mathrm{min}$

Up grinding

Groove geometry:

$\mathrm{d}_{\mathrm{w}}=12 \mathrm{~mm}$

$\mathrm{t}_{\mathrm{n}}=2.5 \mathrm{~mm}$

$\lambda=0 \circ$

$\lambda_{\mathrm{v}}=2 \circ$

Figure 13. Influence of the area-related material removal $\mathrm{V}^{\prime \prime} \mathrm{Sb}$ on the grinding forces. 


\section{Interactions between the Sharpening Parameters}

Besides the influence of the individual significant sharpening parameters, the parameter interactions also affect the sharpening process and thereby the formation of the grinding wheel topography. In particular, the grain size of the sharpening block $\mathrm{d}_{\mathrm{kSb}}$ and the area-related material removal in sharpening $\mathrm{V}^{\prime \prime}$ Sb depend on each other, as shown in Figure 14. The influence of the grain size of the sharpening block $d_{k S b}$ on the reduced peak height Spk largely depends on the area-related material removal in sharpening V" $\mathrm{sb}$. With low area-related material removal, the grain size of the sharpening block has no influence on the Spk value, whereas with high material removal strong fluctuations in the Spk value could be observed depending on the grain size of the sharpening block $d_{\mathrm{kSb}}$. For $\mathrm{V}^{\prime \prime} \mathrm{Sb}=0.12 \mathrm{~mm}^{3} / \mathrm{mm}^{2}$, the Spk value was almost constant over the grain size of the sharpening block $\mathrm{d}_{\mathrm{kSb}}$. Only with increasing material removal of the sharpening block did the influence of the grain size of the sharpening block $\mathrm{d}_{\mathrm{kSb}}$ become more striking.

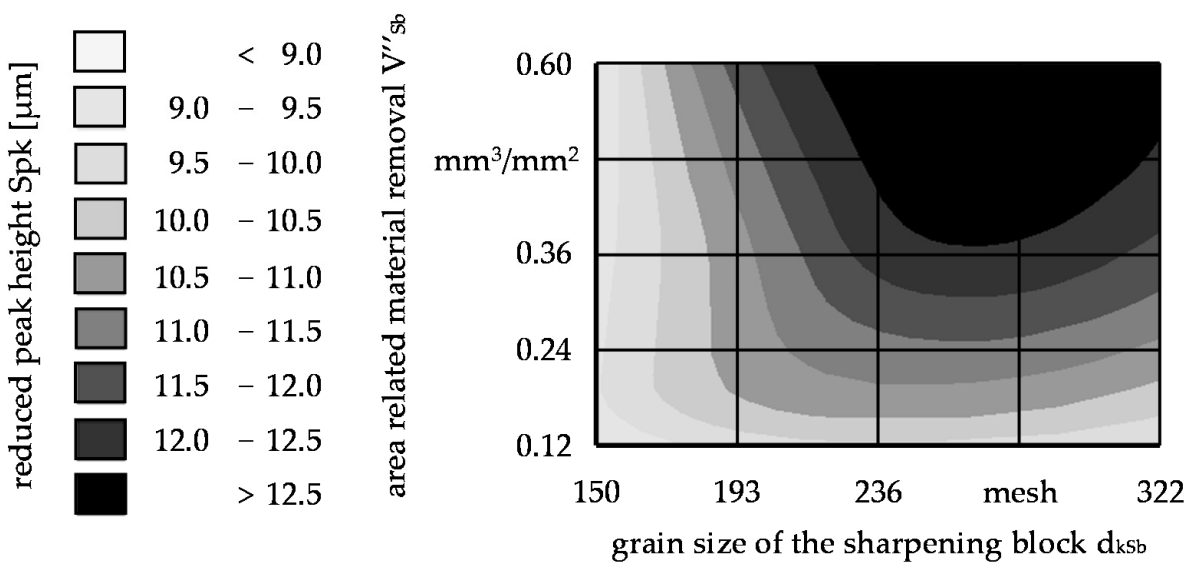

Figure 14. Influence of the interaction between $\mathrm{d}_{\mathrm{kSb}}$ and $\mathrm{V}_{\mathrm{Sb}}$ on the reduced peak height Spk.

The static number of cutting edges $\mathrm{N}_{\text {stat }}$ also depends highly on the area-related material removal in sharpening $\mathrm{V}^{\prime \prime} \mathrm{Sb}$ and the grain size of the sharpening block $\mathrm{d}_{\mathrm{kSb}}$, as seen in Figure 15. For coarse grains of the sharpening block, a slight decrease in the static number of cutting edges $\mathrm{N}_{\text {stat }}$ could been obtained with increasing area-related material removal in sharpening $\mathrm{V}^{\prime \prime} \mathrm{Sb}$. The behavior was reversed for small grain sizes of the sharpening block $\mathrm{d}_{\mathrm{kSb}}$. A high static number of cutting edges $\mathrm{N}_{\text {stat }}$ could be obtained by a combination of small grains and high material removal V" $\mathrm{sb}$. However, it should be noted that a high static number of cutting edges $\mathrm{N}_{\text {stat }}$ is not necessarily equivalent to a rough grinding wheel.
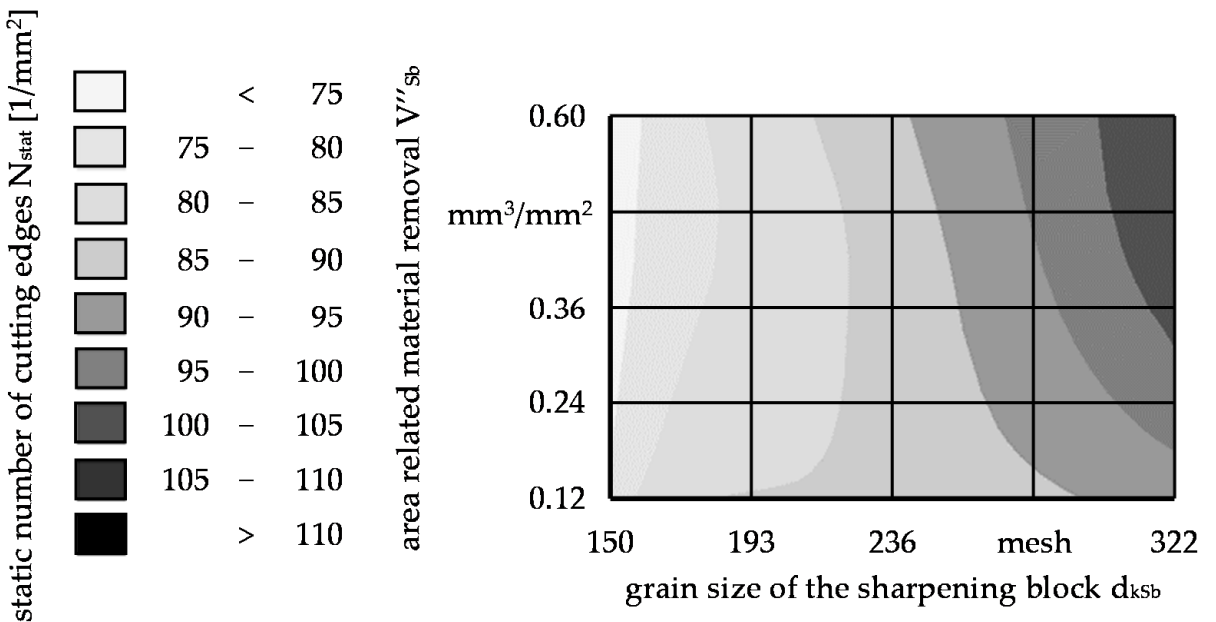

Figure 15. Influence of the interaction between $\mathrm{d}_{\mathrm{kSb}}$ and $\mathrm{V}_{\mathrm{Sb}}$ on the static number of cutting edges $\mathrm{N}_{\text {stat }}$. 
The analysis of the interactions between the sharpening parameters on the grinding wheel topography makes it clear that the sharpening process cannot be modeled in sufficient quality by the influences of individual sharpening parameters.

\section{Process Model}

A process model based on regression analysis was developed by using the experimental results. The required data were determined in the form of topography characteristics. The aim of the process model is to provide the user with the necessary information for a quick and target sharpening process in order to achieve the grinding wheel topography in the stationary state, which depends on various grinding parameters. Therefore, a functional relationship between the input and output variables was developed by using regression equations. The input variables correspond to the three identified significant sharpening parameters, and the output parameters correspond to the determined topography characteristics. A regression equation was developed for each topography characteristic, which are shown in Table 4.

Table 4. Regression equation and model accuracy $\mathrm{R}^{2}$

\begin{tabular}{|c|c|c|c|c|}
\hline \multicolumn{4}{|c|}{ Regression Equations for the Process Model } & \multirow{2}{*}{$\begin{array}{l}\mathbf{R}^{2}[\%] \\
81.70\end{array}$} \\
\hline Spk & $=$ & $\begin{array}{l}- \\
- \\
-\end{array}$ & $\begin{array}{c}0.6235+0.1049 \cdot \mathrm{d}_{\mathrm{kSb}}+0.1733 \cdot \mathrm{l}_{\mathrm{Sb}} 8.6904 \cdot \mathrm{V}^{\prime \prime}{ }_{\mathrm{Sb}}+1.1446 \cdot \\
\ln \left(\mathrm{V}^{\prime \prime}{ }_{\mathrm{Sb}}\right) 0.0001967 \cdot \mathrm{d}_{\mathrm{kSb}}{ }^{2}-0.0006841 \cdot \mathrm{d}_{\mathrm{kSb}} \cdot \mathrm{l}_{\mathrm{Sb}} 0.03502 \cdot \\
\mathrm{d}_{\mathrm{kSb}} \cdot \mathrm{V}_{\mathrm{Sb}}\end{array}$ & \\
\hline Svk & $=$ & $\begin{array}{l}+ \\
- \\
-\end{array}$ & $\begin{array}{c}6.5563-0.02116 \cdot \mathrm{d}_{\mathrm{kSb}}-0.01012 \cdot \mathrm{l}_{\mathrm{Sb}}+9.8642 \cdot \mathrm{V}^{\prime \prime} \mathrm{Sb} \\
4.8223 \cdot \ln \left(\mathrm{V}_{\mathrm{Sb}}^{\prime \prime}+0.5187\right)-0.00003715 \cdot \mathrm{d}_{\mathrm{kSb}}{ }^{2} 0.02201 \\
\mathrm{~d}_{\mathrm{kSb}} \cdot \mathrm{V}_{\mathrm{Sb}}^{\prime \prime}\end{array}$ & 83.03 \\
\hline Sk & $=$ & + & $\begin{array}{c}14.0244+0.0293 \cdot \mathrm{d}_{\mathrm{kSb}}-0.06015 \cdot \mathrm{l}_{\mathrm{Sb}}+5.9868 \cdot \mathrm{V}^{\prime \prime} \mathrm{Sb} \\
0.00009004 \cdot \mathrm{d}_{\mathrm{kSb}}{ }^{2}-0.02032 \cdot \mathrm{d}_{\mathrm{kSb}} \cdot \mathrm{V}^{\prime \prime} \mathrm{Sb}\end{array}$ & 83.25 \\
\hline $\mathrm{V}^{\prime \prime} \mathrm{sp}$ & $=$ & + & $\begin{array}{c}6.6405+0.0263 \cdot \mathrm{d}_{\mathrm{kSb}}-0.02019 \cdot \mathrm{l}_{\mathrm{Sb}}-0.7624 \cdot \mathrm{V}^{\prime \prime} \mathrm{Sb} \\
0.00006683 \cdot \mathrm{d}_{\mathrm{kSb}}{ }^{2}-0.01145 \cdot \mathrm{d}_{\mathrm{kSb}} \cdot \mathrm{V}_{\mathrm{Sb}}\end{array}$ & 59.05 \\
\hline $\mathrm{Sa}$ & $=$ & + & $\begin{array}{c}5.1656+0.01222 \cdot \mathrm{d}_{\mathrm{kSb}}-0.2179 \cdot \ln \left(\mathrm{l}_{\mathrm{Sb}}\right)+0.2070 \\
\ln \left(\mathrm{V}_{\mathrm{Sb}}\right) 0.00003312 \cdot \mathrm{d}_{\mathrm{kSb}} 2\end{array}$ & 73.05 \\
\hline $\mathrm{N}_{\text {stat }}$ & $=$ & - & $\begin{array}{c}12.1668+0.1231 \cdot \mathrm{l}_{\mathrm{Sb}}-42.9860 \cdot \mathrm{V}^{\prime \prime} \mathrm{Sb}+17.7303 \cdot \ln \left(\mathrm{d}_{\mathrm{kSb}}\right) \\
0.2037 \cdot \mathrm{d}_{\mathrm{kSb}} \cdot \mathrm{V}_{\mathrm{Sb}}\end{array}$ & 92.06 \\
\hline $\mathrm{K}$ & $=$ & $\begin{array}{l}+ \\
+ \\
+\end{array}$ & $\begin{array}{c}9.736+0.6390 \cdot \mathrm{d}_{\mathrm{kSb}}+0.09534 \cdot \mathrm{l}_{\mathrm{Sb}}-4.5180 \cdot \mathrm{V}^{\prime \prime} \mathrm{Sb} 0.8215 \\
\cdot \ln \left(\mathrm{V}_{\mathrm{Sb}}^{\prime \prime}\right)-0.0001315 \cdot \mathrm{d}_{\mathrm{kSb}}{ }^{2}-0.0005046 \cdot \mathrm{d}_{\mathrm{kSb}} \cdot \mathrm{l}_{\mathrm{Sb}} \\
0.02021 \cdot \mathrm{d}_{\mathrm{kSb}} \cdot \mathrm{V}_{\mathrm{Sb}}\end{array}$ & 70.06 \\
\hline
\end{tabular}

The coefficient of determination $\mathrm{R}^{2}$ makes it possible to evaluate the accuracy of the established regression equations. It indicates how suitable the models are for explaining the total variation of the determined topography characteristics. The established regression equations differ greatly in their suitability for the process model. For the static number of cutting edges $\mathrm{N}_{\text {stat }}$ a high model accuracy was realized with a compact equation. Other parameters, in particular the area-related chip space volume V" sp, are less suitable for modeling because of their poor accuracy. The interaction between the grain size $\mathrm{d}_{\mathrm{kSb}}$ and the area-related material removal in sharpening $\mathrm{V}^{\prime \prime} \mathrm{sb}$ has been identified as a significant influencing factor.

The determined regression equations were then used to implement the process model by using the software MATLAB of MathWorks, Natick, MA, USA. For this purpose, a graphical user interface (GUI) was developed, which enables easy handling of the process model. The model can be used to predict the required sharpening parameters for certain target topographies or vice versa, returning the topography characteristics for explicit sharpening parameters. The desired sharpening and topography parameters were calculated by minimizing the quadratic error of the process model. Figure 16 shows the graphical user interface of the process model. Any combination of topography characteristic and process 
parameter can be used as input variable. It should be noted that at least three parameters must be specified by the user in order to use the process model optimally. The algorithm automatically calculates the missing parameters with the best possible adaptation to the process model. In order to evaluate the accuracy, the value "error" is additionally calculated. The developed process model thus represents a tool for planning and illustrating the sharpening process.
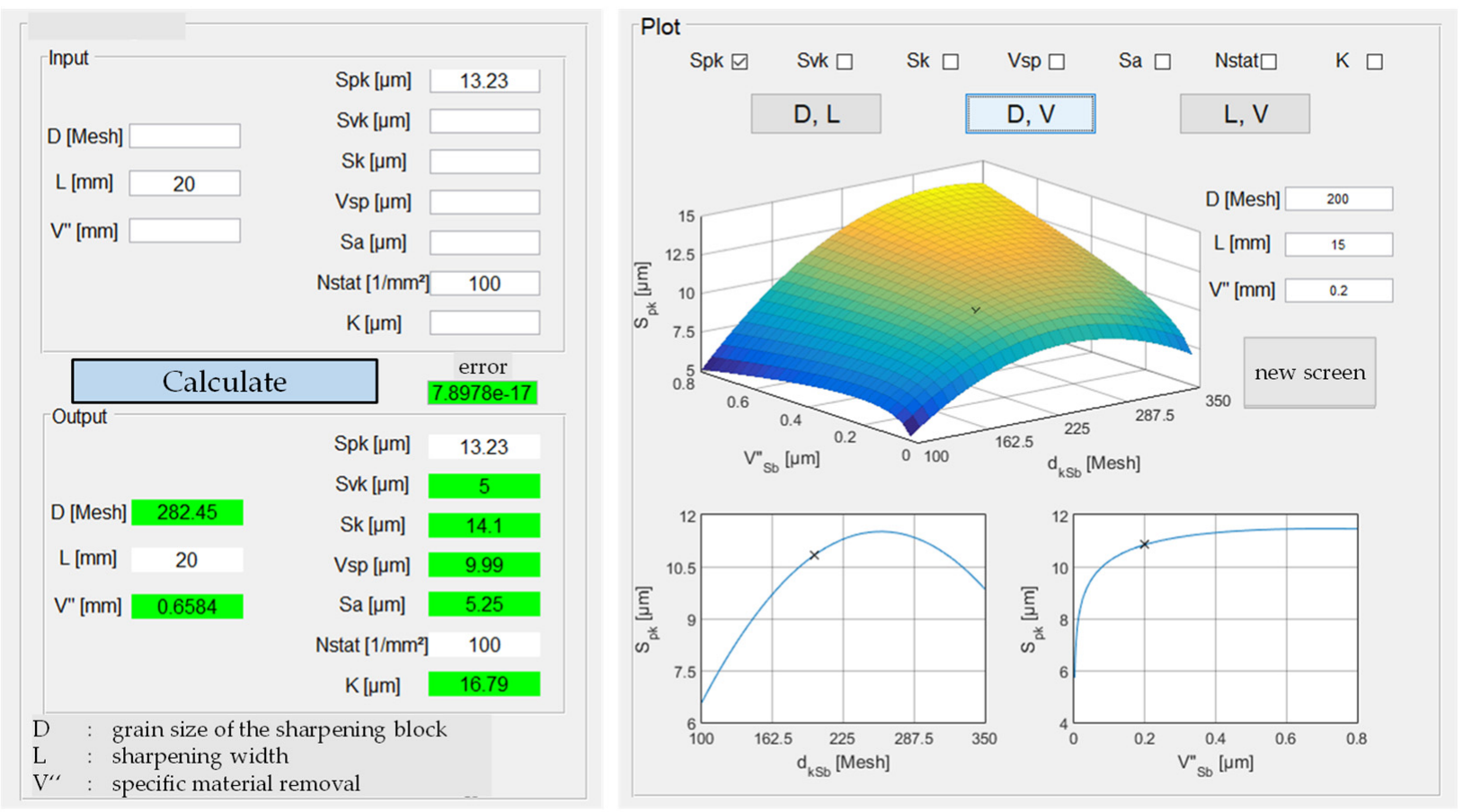

Figure 16. Graphical user interface of the process model.

Further technological investigations were carried out to verify the process model. Therefore, the topography characteristics calculated for certain sharpening parameters are listed in Table 5.

Table 5. Sharpening parameters for the verification of the process model.

\begin{tabular}{cccc}
\hline Experiment & $\mathbf{d}_{\mathbf{k S b}}$ & $\mathbf{1}_{\mathbf{S b}}$ & $\mathbf{V}^{\mathbf{\prime}} \mathbf{S b}$ \\
\hline & mesh & $\mathrm{mm}$ & $\mu \mathrm{m}$ \\
\hline 1 & 150 & 25 & 0.40 \\
2 & 180 & 09 & 0.55 \\
\hline
\end{tabular}

Afterwards, sharpening experiments were carried out with the specified parameters, and the topography characteristics were determined by means of imprints. Figure 17 shows the calculated topography characteristics and those obtained from the sharpening experiments. It becomes clear that the calculated topography characteristics were close to the experimentally achieved values. The percentage difference was less than $10 \%$ for all determined topography characteristics. Thus, the process model is suitable for the targeted setting of the grinding wheel topography. 


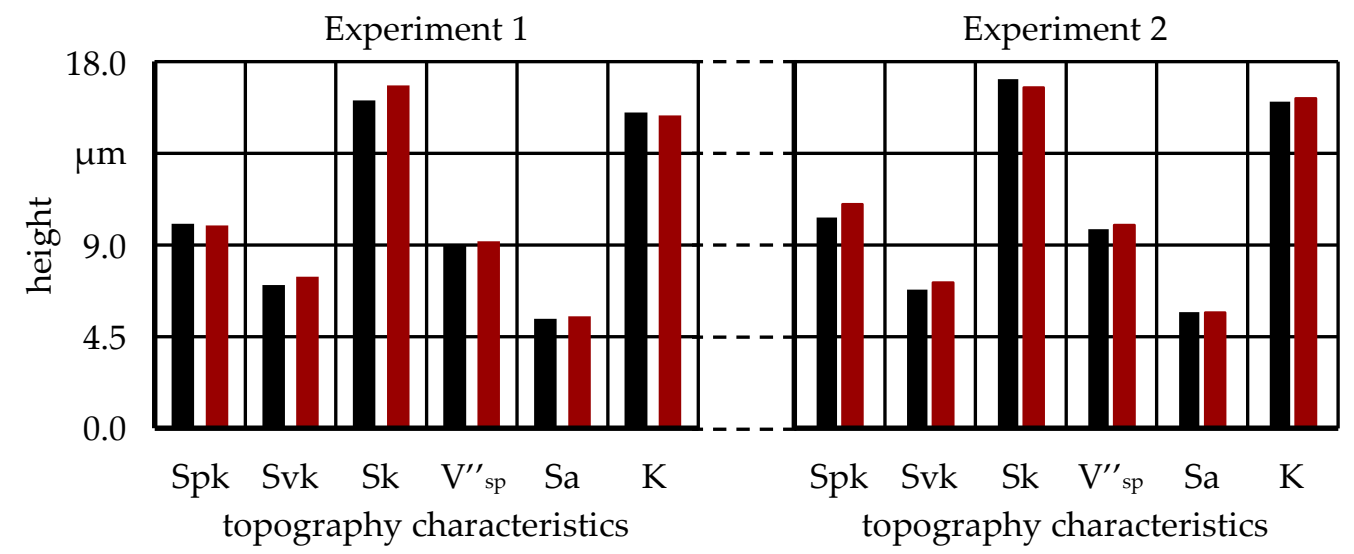

Figure 17. Calculated and experimental obtained topography characteristics.

\section{Conclusions}

Super abrasive grinding wheels require a sharpening process to reset the bond material and to obtain the necessary cutting grains and chip space. The study clearly shows the correlations between the sharpening parameters and the resulting grinding wheel topography, which can be used to model the sharpening process. It was found that the sharpening block width $l_{S b}$, the grain size of the sharpening block $d_{k S b}$ and the area-related material removal in sharpening $\mathrm{V}^{\prime \prime} \mathrm{Sb}$ are the main parameters that influence the grinding wheel topography. Further experiments were carried out to quantify the influence of the identified significant parameters. The investigation showed that the material removal $\mathrm{V}^{\prime \prime} \mathrm{Sb}$ and the grain size of the sharpening block $\mathrm{d}_{\mathrm{kSb}}$ significantly influenced the topography characteristics, while the sharpening block width $l_{\mathrm{Sb}}$ only caused minor changes in the grinding wheel topography. Furthermore, the interactions between the sharpening parameters were analyzed.

Based on the experimental results an empirical process model was developed that enables the user to achieve a target setting of the grinding wheel topography. As a result, manual sharpening processes based on the experience of individual process operators can be avoided. The industrial application of the developed CNC-controlled sharpening process enables a time-optimized, process-reliable and resource-efficient setting of the surface topography. Furthermore, the initial unsteady grinding behavior can be shorted by the target setting of the grinding wheel topography and ensures an almost constant workpiece quality. In addition, complex preliminary sharpening processes can be avoided by using the developed process model.

Author Contributions: Conceptualization, E.U.; Formal analysis, E.U. and A.M.; Funding acquisition: E.U.; Investigation, A.M.; Methodology, A.M.; Project administration, E.U. and A.M.; Supervision, E.U.; Validation, A.M.; Writing—original draft, E.U. and A.M.; Writing—review \& editing, E.U. and A.M. All authors have read and agreed to the published version of the manuscript.

Funding: This research was funded by VDW Forschungsinstitute. V. und the AiF grant number IGF 19531 N/1.

\section{Institutional Review Board Statement: Not applicable.}

Informed Consent Statement: Not applicable.

Data Availability Statement: Not applicable.

Conflicts of Interest: The authors declare no conflict of interest. 


\section{Appendix A}

In Table A1 the parameters are listed for the experimental investigation in order to identify the significant sharpening parameters.

Table A1. Sharpening parameters for experimental investigation to identify the significant sharpening parameters.

\begin{tabular}{|c|c|c|c|c|c|}
\hline $\begin{array}{c}\text { Experiment } \\
\text { Nr. }\end{array}$ & $\begin{array}{l}\text { Grain Size } \\
\text { of the } \\
\text { Sharpening } \\
\text { Block } d_{k S b}\end{array}$ & $\begin{array}{c}\text { Sharpening } \\
\text { Block Width } \\
1_{\text {Sb }}\end{array}$ & $\begin{array}{c}\text { Material } \\
\text { Removal } \\
\text { Rate } Q^{\prime \prime} \mathrm{sb}\end{array}$ & $\begin{array}{c}\text { Material } \\
\text { Removal } \\
\text { V"Sb }\end{array}$ & $\begin{array}{l}\text { Grinding } \\
\text { Wheel Cir- } \\
\text { cumferential } \\
\text { Speed } V_{\text {sSb }}\end{array}$ \\
\hline- & mesh & $\mathrm{mm}$ & $\mathrm{mm}^{3} /\left(\mathrm{mm}^{2} \cdot \mathrm{s}\right)$ & $\mathrm{mm}^{3} / \mathrm{mm}^{2}$ & $\mathrm{~m} / \mathrm{s}$ \\
\hline $\begin{array}{c}1 \\
\text { (initial state) }\end{array}$ & - & - & - & - & - \\
\hline 2 & 180 & 25.0 & 0.016 & 0.159 & 10 \\
\hline 3 & 180 & 25.0 & 0.016 & 0.159 & 17 \\
\hline 4 & 180 & 25.0 & 0.016 & 0.382 & 10 \\
\hline 5 & 180 & 25.0 & 0.016 & 0.382 & 17 \\
\hline 6 & 180 & 25.0 & 0.032 & 0.159 & 10 \\
\hline 7 & 180 & 25.0 & 0.032 & 0.159 & 17 \\
\hline 8 & 180 & 25.0 & 0.032 & 0.382 & 10 \\
\hline 9 & 180 & 25.0 & 0.032 & 0.382 & 17 \\
\hline 10 & 180 & 12.5 & 0.016 & 0.159 & 10 \\
\hline 11 & 180 & 12.5 & 0.016 & 0.159 & 17 \\
\hline 12 & 180 & 12.5 & 0.016 & 0.382 & 10 \\
\hline 13 & 180 & 12.5 & 0.016 & 0.382 & 17 \\
\hline 14 & 180 & 12.5 & 0.032 & 0.159 & 10 \\
\hline 15 & 180 & 12.5 & 0.032 & 0.159 & 17 \\
\hline 16 & 180 & 12.5 & 0.032 & 0.382 & 10 \\
\hline 17 & 180 & 12.5 & 0.032 & 0.382 & 17 \\
\hline 18 & 220 & 25.0 & 0.016 & 0.159 & 10 \\
\hline 19 & 220 & 25.0 & 0.016 & 0.159 & 17 \\
\hline 20 & 220 & 25.0 & 0.016 & 0.382 & 10 \\
\hline 21 & 220 & 25.0 & 0.016 & 0.382 & 17 \\
\hline 22 & 220 & 25.0 & 0.032 & 0.159 & 10 \\
\hline 23 & 220 & 25.0 & 0.032 & 0.159 & 17 \\
\hline 24 & 220 & 25.0 & 0.032 & 0.382 & 10 \\
\hline 25 & 220 & 25.0 & 0.032 & 0.382 & 17 \\
\hline 26 & 220 & 12.5 & 0.016 & 0.159 & 10 \\
\hline 27 & 220 & 12.5 & 0.016 & 0.159 & 17 \\
\hline 28 & 220 & 12.5 & 0.016 & 0.382 & 10 \\
\hline 29 & 220 & 12.5 & 0.016 & 0.382 & 17 \\
\hline 30 & 220 & 12.5 & 0.032 & 0.159 & 10 \\
\hline 31 & 220 & 12.5 & 0.032 & 0.159 & 17 \\
\hline 32 & 220 & 12.5 & 0.032 & 0.382 & 10 \\
\hline 33 & 220 & 12.5 & 0.032 & 0.382 & 17 \\
\hline
\end{tabular}




\section{References}

1. Schröer, N. Spannutschleifen von Hartmetall-Schaftwerkzeugen mit Gradierten Schleifscheiben; Fraunhofer Verlag: Stuttgart, Germany, 2018.

2. Wegener, K. Conditioning and Monitoring of Grinding Wheels. CIRP Ann. Manuf. Technol. 2011, 60, 757-777. [CrossRef]

3. Klocke, F. Grundlagen zum Schneideneingriff. In Fertigungsverfahren 2; Springer Vieweg: Berlin/Heidelberg, Germany, 2017; pp. 5-19.

4. Barth, S.; Klocke, F. Influence of the grinding wheel topography on the thermo-mechanical stress collective in grinding. Inventions 2017, 24, 34. [CrossRef]

5. Rabiey, M.; Maerchy, P. Investigation on surface integrity of steel din 100 cr6 by grinding using cbn tool. Procedia CIRP 2020, 87 , 192-197. [CrossRef]

6. Thanedar, A.; Dongre, G.G.; Singh, R.; Joshi, S.S. Surface integrity investigation including grinding burns using barkhausen noise (BNA). J. Manuf. Process. 2017, 30, 226-240. [CrossRef]

7. Uhlmann, E. Tiefschleifen Hochfester Keramischer Werkstoffe. Reihe Produktionstechnik Berlin, Forschungsberichte für die Praxis, Bd. 129. Hrsg. G. Spur; Carl Hanser Verlag: München, Germany, 1994.

8. Jacobs, U. Beitrag zum Einsatz von Schleifscheiben mit Kubisch-Kristallinem Bornitrid als Schneidstoff. Ph.D. Thesis, Technische Universität Braunschweig, Braunschweig, Germany, 1979.

9. Schleich, H. Schärfen von Bornitridschleifscheiben. Ph.D Thesis, RWTH Aachen, Aachen, Germany, 1982.

10. Stuff, D. Einsatzvorbereitung Keramisch Gebundener CBN-Schleifscheiben. Fortschritt-Berichte VDI Reihe 2 Nr. 417; VDI-Verlag: Düsseldorf, Germany, 1997.

11. Ohmori, H.; Nakagawa, T. Grinding of Silicon using cast iron fiber bonded wheel. In Proceedings of the Autumn Conference of JSPE, Tokyo, Japan, 1987; p. 687. Available online: https:/ / ci.nii.ac.jp/naid/10003870204/.

12. Shore, P. ELID for efficient grinding of super smooth surfaces. IDR 1993, 6, 318-322.

13. Falkenberg, Y. Elektroerosives Schärfen von Bornitridschleifscheiben. Ph.D. Thesis, Leibniz Universität Hannover, Hannover, Germany, 1998.

14. Yin, S.; Ohmori, H.; Dai, Y.; Uehara, Y.; Chen, F.; Tang, H. ELID grinding characteristics of glass-ceramic materials. Int. J. Mach. Tools Manuf. 2009, 49, 333-338. [CrossRef]

15. Saleh, T.; Bishwas, I.; Rahman, M. Efficient dressing of the wheel in ELID grinding by controllable voltage with force feed back. Int. J. Adv. Manuf. Technol. 2010, 46, 123-130. [CrossRef]

16. Hübert, C. Schleifen von Hartmetall- und Vollkeramik-Schaftfräsern. In Berichte aus dem Produktionstechnischen Zentrum Berlin; Uhlmann, E.H., Ed.; Fraunhofer: Stuttgart, Germany, 2012.

17. DIN EN ISO 25178-2. Geometrische Produktspezifikation (GPS)—Oberflüchenbeschaffenheit: Flächenhaft-Teil 2: Begriffe und OberflüchenKenngrößen, Beuth: Berlin, Germany, 2012.

18. Kleppmann, W. Taschenbuch Versuchsplanung: Produkte und Prozesse Optimieren; Hanser: München, Germany, 2013.

19. Siebertz, K.; van Bebber, D.; Hochkirchen, T. Statistische Versuchsplanung: Design of Experiments (DoE); Springer: Berlin/Heidelberg, Germany, 2010. 